\title{
Therapeutic Effects of Korean Red Ginseng Extract in Egyptian Patients with Chronic Liver Diseases
}

\author{
Mosaad A. Abdel-Wahhab ${ }^{1 *}$, Khaled Gamil ${ }^{2}$, Ahmed A. El-Kady ${ }^{1}$, Aziza A. El-Nekeety ${ }^{1}$, and \\ Khayria M. Naguib ${ }^{1}$ \\ ${ }^{1}$ Food Toxicology \& Contaminants Department, National Research Centre, Dokki, Cairo, Egypt \\ ${ }^{2}$ National Liver Institute, Monoufia University, Monoufia, Egypt
}

Hepatocellular carcinoma (HCC) is the fifth most common malignancy in the world and complicates liver cirrhosis related to hepatitis $\mathrm{C}$ virus (HCV) in many cases. We evaluated the therapeutic effect of Korean red ginseng extract (KGE) in patients with chronic liver diseases. Thirty male and female patients with HCC and another thirty with liver cirrhosis were included. Each category was divided into two groups; the first was used as control group, and received medical therapy only and the second group received the medical therapy supplemented with KGE capsules. The treated group with HCC received three KGE capsules/day $(900 \mathrm{mg})$ while the treated group with $\mathrm{HCV}$ received two KGE capsules/day $(600 \mathrm{mg})$ for 11 weeks along with their medical therapy. All patients were subjected to clinical examination and laboratory investigations, including liver function tests (at baseline, after 6 weeks of treatment and at the end of the study) and abdominal ultrasonography. Patients showing focal hepatic lesions were subjected to triphasic spiral abdominal computerized tomography and alpha-fetoprotein (AFP). HCV RNA was determined quantitatively by Roche for patients in the HCV group. Results showed that the medical therapy alone failed to normalize the liver enzymes or decrease the virus concentration. KGE administration induced a significant improvement in liver function tests, decreased the tumor marker (AFP) levels, and decreased the viral titers in HCV patients. Thus, KGE demonstrated powerful therapeutic effects against HCV and liver cancer.

Keywords: Panax ginseng, Neoplasms, Egypt, Hepacivirus, Korean ginseng, Liver diseases

\section{INTRODUCTION}

Hepatocellular carcinoma is one of the world's deadliest cancers, ranking third among all cancer-related mortality. Most cases occur in Asia and sub-Saharan Africa, where viral hepatitis is endemic. The incidence is rising in the West, likely due to the increase in patients infected with hepatitis $\mathrm{C}$ during the latter half of the last century [1]. This incidence is increasing worldwide, between 3\% and $9 \%$ annually [2]. In Egypt, the annual prevalence of hepatocellular carcinoma (HCC) has increased significantly during the past decade. HCC has been reported to account for about $4.7 \%$ of the chronic liver disease patients, where the epidemiology of HCC is characterized by marked demographic and geographic variations [3]. The liver, unique in its capacity for regeneration following injury, also gives rise to this malignancy, commonly associated with an inflammatory state of advanced fibrosis or cirrhosis. Potentially curative therapies can be offered to approximately $30 \%$ of patients, but these are complicated by a high rate of recurrence [4].

Encouraging progress has been made in understanding cc This is an Open Access article distributed under the terms of the Creative Commons Attribution Non-Commercial License (http://creativecommons.org/licenses/by-nc/3.0/) which permits unrestricted non-commercial use, distribution, and reproduction in any medium, provided the original work is properly cited.
Received 18 Oct. 2010, Revised 7 Feb. 2011, Accepted 7 Feb. 2011

*Corresponding author

E-mail: mosaad_abdelwahhab@yahoo.com

Tel: +20-2-2283-1943, Fax: +20-2-3337-0931 
the molecular pathogenesis of cancer [1,4]. Discoveries of the signal transduction pathways, cascades of proteinprotein interactions transmitting information from the cell surface to the nucleus, and of their link to tumour biology, are particularly impressive. Several key mouse models have been instrumental in defining the pathogenesis of $\mathrm{HCC}$ by introducing genetic alterations into one or more aetiological pathways that can be targeted exclusively to the liver. Moreover, these programmed manipulations can be introduced systematically, not only in this specific organ, but also at defined times during development, growth, and aging of the liver.

For more than 3,000 years, ginseng has been used in Asia for the treatment of various medical disorders. Since the 18th century, it has been one of the most commonly used herbal medicines in Europe and North America [5]. According to a survey study, ginseng is the second most popular herbal medicine in the United States [6]. Several types of ginseng have been identified to date, including those of the Panax genus. The best characterized species in this genus are Panax ginseng C. A. Meyer [5]. Recently, 20-O-( $\beta$-D-glucopyranosyl)-20(S)-protopanaxadiol (IH901), a novel ginseng saponin metabolite, formed from ginsenosides $\mathrm{Rb} 1, \mathrm{Rb} 2$, and $\mathrm{Rc}$ was isolated and purified after giving ginseng extract orally to humans and rats [7]. IH-901 has been shown to enhance the efficacy of anticancer drugs in cancer cell lines previously resistant to several anticancer drugs $[8,9]$, to exhibit antigenotoxic and anticlastogenic activity in rats concurrently treated with benzo(a)pyrene [10], and to induce apoptosis $[11,12]$. These studies found that the antitumor activity of IH-901 is attributable to the induction of apoptosis. The aim of the current study was to evaluate the therapeutic effects of Korean red ginseng extract in Egyptian patients with chronic liver diseases.

\section{Patients and methods}

After receiving approval from the Ethical Committee of the National Research Center, Egypt, patients were recruited. They signed informed consent forms at the Hepatology Outpatient Clinic of the Internal Medicine Department, National Liver Institute, Monoufia University. The study was conducted from May till August 2008.

A full history was taken including determining whether there was a past history of schistosomiasis, as was a thorough clinical examination, laboratory investigations (liver function tests: aspartate transaminase (AST) and alanine transaminase (ALT), serum bilirubin (total and direct), serum total proteins, serum albumin, prothrombin concentration), and abdominal ultrasonography. Patients with focal hepatic lesions were subjected to triphasic spiral abdominal computed tomography (CT) and alpha-fetoprotein (if not previously done). Hepatitis C virus (HCV) RNA was determined quantitatively by Roche for patients in the HCV group. All biochemical analyses were carried out at Food Toxicology \& Contaminants Department, National Research Center. Then, patients were enrolled, according to the following inclusion/exclusion criteria.

\section{Inclusion criteria}

Patients (1.) must be between 40 and 80 years old, (2.) of either gender, (3.) be diagnosed with cirrhotic liver disease, and (4.) have evidence of a malignant focal hepatic lesion.

\section{Exclusion criteria}

Patients were excluded for the following reasons: (1.) they were diagnosed with a systemic disease, such as a renal, cardiac, or respiratory disease, (2.) patients had malignancies that originated extrahepatically or (3.) if they displayed hepatic encephalopathy at time of the study.

Finally, we were left with thirty patients who had HCC and a mean age of $52.3 \pm 8.1$ and thirty patients who had HCV with a mean age of $47.8 \pm 18.2$. The HCC patients within each category were divided into two groups (15 patients/group), and the first group served as a control (11 males, 4 females). The control group received only their medication with no ginseng administration, while the second group served as the treated group (11 males, 4 females) and received their medical treatment, supplemented with three ginseng capsules $(900 \mathrm{mg} /$ day). The HCV patients were also divided into two groups (15 patients/group); the first group served as a control (8 males, 7 females) and received their medical treatments and no ginseng. The second group served as the treated group and received their medical treatments supplemented with two ginseng capsules per day $(600 \mathrm{mg} /$ day $)$. All patients continued the study for 11 weeks. During this period, all laboratory investigations were conducted at baseline, at the sixth week (half way) and at the eleventh week (end of study period). These laboratory investigations included a biochemical analysis and the other tests suggested by the physicians. Two females in the second group of HCC patients stopped taking ginseng on day 51 of the study. Thus, we excluded these two females from the control group, and the study continued with the remaining thirteen patients (11 males, 2 females). On the other hand, six patients in the HCV group stopped taking ginseng on day 25 and did not complete the study. Consequently, we discarded these six patients from the control group and 
the study continued with the other patients (4 males and 5 females). All laboratory investigations were carried out at the Internal Medicine Department labs. These labs operate under a quality assurance system according to ISO/IEC 17025.

\section{Statistical analyses}

The compiled data were analyzed using EPI Info ver. 6.2 (CDC, Atlanta, GA, USA) and the SPSS ver. 7.5 (SPSS Inc., Chicago, IL, USA). ANOVA and the chi-squared test were used to study the pattern of distribution of different variables. Multiple correlation coefficients $\{\mathrm{r}\}$ were used to determine the correlation of the studied parameters to each other. A $p$-value of less than 0.05 was considered to indicate statistical significance. All data are presented as means \pm SE.

\section{RESULTS}

The present controlled study involved 26 patients suffering from $\mathrm{HCC}$ and 18 patients suffering from liver cirrhosis. Demographic data including age, gender, smoking, and residence between the HCC group and cirrhotics is presented in Table 1. Results indicated that the mean age of HCC patients $(52.3 \pm 12.1)$ was significantly higher than that of cirrhotics $(47.8 \pm 18.2)$. The distribution of gender among the HCC and cirrhotic patients showed that percentage of males $(42.3 \%$ and $44.4 \%)$ was lower than that of females $(57.7 \%$ and $55.6 \%)$, respectively. However, the number of non-smoking cirrhotic patients (72.2\%) was higher than the HCC patients $(61.5 \%)$.

Table 1. Distribution of age, gender, residence, and smoking between the hepatocellular carcinoma (HCC) group and cirrhotic patients

\begin{tabular}{clcc}
\hline \multirow{4}{*}{ Age } & & HCC patients $(n=26)$ & Cirrhotics $(n=18)$ \\
\hline \multirow{5}{*}{ Gender } & & $52.3 \pm 12.1$ & $47.8 \pm 18.2$ \\
& & $10(38.5)$ & $8(44.4)$ \\
& Male & $16(61.5)$ & $10(55.6)$ \\
& Female & $11(42.3)$ & $8(44.4)$ \\
Smoking & & & $10(55.6)$ \\
& Yes & $6(23.1)$ & $3(16.7)$ \\
& Ex & $4(15.4)$ & $2(11.1)$ \\
& $n$ & $16(61.5)$ & $13(72.2)$ \\
& & & $7(38.9)$ \\
& Rural & $14(53.9)$ & $11(61.1)$ \\
\hline
\end{tabular}

Values are presented as mean \pm SE or number (\%).
Regarding the area of residence, the number of HCC patients was higher in rural areas (53.9\%) compared with cirrhotic patients (38.9\%). However, the number of urban patients was higher in those with cirrhosis (61.1\%) than those with HCC (46.2\%).

Radiological (ultrasound and spiral CT) data concerning the focal hepatic lesions are presented in Table 2. Results revealed that the focal lesions in the right lobe were significantly more likely than either bilateral multiple focal lesions and focal lesions in left lobe. The percentage of patients having $\mathrm{HCC}$ in addition to liver cirrhosis (65.4\%) was significantly higher than that of those without liver cirrhosis (34.6\%). Furthermore, the absence of portal vein thrombosis was significantly higher.

The classification of patients according to Child-Pugh scoring system is presented in Table 3 . The results indicated that the percentage of grade $\mathrm{C}$ among $\mathrm{HCC}$ patients $(57.7 \%)$ was the highest, followed by grade B $(30.8 \%)$ and grade A (11.5\%). However, the only significant difference was detected between percentages of patients in grades B and A, and between those patients in grades $\mathrm{C}$ and $\mathrm{A}$. Among the group with cirrhosis, there was no significant difference regarding Child-Pugh classification between class $\mathrm{A}$ and $\mathrm{B}$, although there was a significant difference between class $\mathrm{C}$ and the other two classes.

The biochemical analysis for male and female patients presented in Table 4 revealed that both of the control groups (males and females) and the Korean red ginseng extract (KGE)-treated group (with HCC or cirrhotic) showed a significant increase in ALT at the beginning of the study. Moreover, the increase in ALT activity was more pronounced in females. All patients showed a significant decrease in ALT activity after the administration of KGE capsules at 6 and 11 weeks. Results also indicated that the

Table 2. Results of ultrasonographic data for the hepatocellular carcinoma (HCC) group

\begin{tabular}{llcc}
\hline & & \multicolumn{2}{c}{ HCC patients } \\
\cline { 3 - 4 } Fatty liver & & $n=26$ & $\%$ \\
& & 14 & 53.8 \\
& Right lobe & 7 & 26.9 \\
& Left lobe & 5 & 19.2 \\
Cirrhosis & Both lobes & -- & -- \\
& & & \\
& & 17 & 65.4 \\
Pes & 9 & 34.6 \\
& No & & \\
& & 8 & 30.7 \\
& Yes & 18 & 69.3 \\
\hline
\end{tabular}


Table 3. Classification of patients according to the Child-Pugh scoring system

\begin{tabular}{ccccc}
\hline Child-Pugh score & \multicolumn{2}{c}{ HCC patients } & \multicolumn{2}{c}{ Cirrhotics } \\
\hline & $n=26$ & $\%$ & $n=18$ & $\%$ \\
A & 3 & 11.5 & 3 & 16.7 \\
B & 8 & 30.8 & 5 & 27.7 \\
C & 15 & 57.7 & 10 & 55.6 \\
\hline
\end{tabular}

HCC, hepatocellular carcinoma.

activity of ALT remained increased in the control group and this increase was pronounced at week 11 although these patients received their medication. A significant decrease was found in the group that received their medication plus KGE capsules $(900 \mathrm{mg} /$ day for HCC patients and $600 \mathrm{mg}$ /day for cirrhotics), although the level of the liver enzymes was still higher than the reference range.

The current results also indicated that both groups of patients showed a significant increase in AST activity at the beginning of the study. The activity of this enzyme was higher in males than females and decreased significantly after the administration of KGE. This decrease was $13.4 \%$ at week 6 and $23.4 \%$ after 11 weeks of KGE administration. On the other hand, the activity of AST increased continuously in the control group and reached a maximum by week 11. However, AST levels decreased continuously in the KGE-treated group and reached their minimum by week 11.

The data presented in Table 4 revealed that serum total protein (TP) in the two groups of patients showed an insignificant decrease compared with the reference range $(6.4-8.3 \mathrm{~g} / \mathrm{dL})$. At the beginning of the study, both groups had similar concentrations of serum TP, although it was higher in the group subjected to KGE treatment than the control group. On the sixth week of KGE treatment, TP was increased and reached $6.98 \mathrm{~g} / \mathrm{dL}$ and $7.24 \mathrm{~g} / \mathrm{dL}$ in males and females, respectively. A further increase in serum TP was recorded by the eleventh week of KGE treatment and was $7.44 \mathrm{~g} / \mathrm{dL}$ and $7.66 \mathrm{~g} / \mathrm{dL}$ in males and females, respectively. Serum TP also increased in the control patients during the study period, likely indicating an effect of the medication. However, the combination of KGE treatment plus the medication resulted in a pronounced improvement in the serum TP, which reached the reference range level in both males and females patients with $\mathrm{HCC}$ or cirrhosis.

The effects of KGE administration on serum albumin level in the male and female patients (Table 4) revealed that serum albumin level in both groups was lower than the reference range (3.3-5.0 g/dL). Moreover, the serum albumin level was higher in females than in males of the same group. Administration of KGE capsules $(900 \mathrm{mg} /$ day for HCC patients and $600 \mathrm{mg}$ /day for cirrhotics) elevated the serum albumin level after 6 weeks of administration. However, the administration of KGE at the same dose for both studied groups resulted in a significant improvement in serum albumin level that reached the normal reference range. This improvement was more pronounced in males

Table 4. Effect of ginseng administration on liver function in male and female patients with chronic liver disease during the study period (means \pm SE)

\begin{tabular}{|c|c|c|c|c|c|c|c|}
\hline \multirow{2}{*}{ Parameters } & \multirow{2}{*}{ Gender } & \multicolumn{2}{|c|}{ Baseline } & \multicolumn{2}{|c|}{ 6th week } & \multicolumn{2}{|c|}{11 th week } \\
\hline & & Control & KGE & Control & KGE & Control & KGE \\
\hline \multirow{2}{*}{ ALT (IU/L) } & M & $69.3 \pm 10.4^{\mathrm{a}}$ & $59.2 \pm 8.4^{\mathrm{a}}$ & $69.6 \pm 7.5^{\mathrm{a}}$ & $50.8 \pm 7.2^{\mathrm{b}}$ & $82.9 \pm 8.9^{b}$ & $36.1 \pm 3.9^{c}$ \\
\hline & $\mathrm{F}$ & $77.1 \pm 14.8^{\mathrm{a}}$ & $103.6 \pm 15.7^{\mathrm{a}}$ & $94.7 \pm 15.4^{\mathrm{b}}$ & $85.6 \pm 10.5^{\mathrm{b}}$ & $165.4 \pm 46.5^{\mathrm{c}}$ & $55.0 \pm 6.9^{\mathrm{c}}$ \\
\hline \multirow{2}{*}{$\mathrm{AST}(\mathrm{IU} / \mathrm{L})$} & M & $64.0 \pm 11.4^{\mathrm{a}}$ & $72.8 \pm 9.9^{\mathrm{a}}$ & $71.9 \pm 8.5^{\mathrm{b}}$ & $63.1 \pm 8.7^{\mathrm{b}}$ & $91.3 \pm 8.7^{\mathrm{c}}$ & $55.8 \pm 8.0^{\mathrm{c}}$ \\
\hline & $\mathrm{F}$ & $67.3 \pm 17.1^{\mathrm{a}}$ & $109.6 \pm 19.1^{\mathrm{a}}$ & $78.6 \pm 14.2^{\mathrm{b}}$ & $93.6 \pm 15.1^{\mathrm{b}}$ & $150.9 \pm 26.7^{\mathrm{c}}$ & $74.7 \pm 11.2^{c}$ \\
\hline \multirow{2}{*}{$\mathrm{TP}(\mathrm{g} / \mathrm{dL})$} & M & $5.6 \pm 0.1^{\mathrm{a}}$ & $6.5 \pm 0.1^{\mathrm{a}}$ & $5.9 \pm 0.1^{\mathrm{a}}$ & $7.0 \pm 0.1^{\mathrm{a}}$ & $6.2 \pm 0.1^{\mathrm{b}}$ & $7.4 \pm 0.1^{\mathrm{c}}$ \\
\hline & $\mathrm{F}$ & $5.6 \pm 0.2^{\mathrm{a}}$ & $6.7 \pm 0.1^{\mathrm{a}}$ & $6.0 \pm 0.2^{\mathrm{a}}$ & $7.2 \pm 0.2^{\mathrm{b}}$ & $6.4 \pm 0.2^{\mathrm{b}}$ & $7.7 \pm 0.2^{\mathrm{b}}$ \\
\hline \multirow{2}{*}{ Albumin $(\mathrm{g} / \mathrm{dL})$} & M & $3.2 \pm 0.1^{\mathrm{a}}$ & $3.5 \pm 0.1^{\mathrm{a}}$ & $3.1 \pm 0.1^{\mathrm{a}}$ & $3.5 \pm 0.1^{\mathrm{a}}$ & $3.1 \pm 0.2^{\mathrm{a}}$ & $4.0 \pm 0.1^{\mathrm{b}}$ \\
\hline & F & $3.0 \pm 0.3^{\mathrm{a}}$ & $3.4 \pm 0.2^{\mathrm{a}}$ & $3.2 \pm 0.2^{\mathrm{b}}$ & $3.6 \pm 0.2^{\mathrm{a}}$ & $3.3 \pm 0.2^{\mathrm{c}}$ & $3.9 \pm 0.2^{\mathrm{b}}$ \\
\hline \multirow{2}{*}{$\mathrm{TB}(\mathrm{mg} / \mathrm{dL})$} & M & $1.7 \pm 0.2^{\mathrm{a}}$ & $1.5 \pm 0.2^{\mathrm{a}}$ & $2.0 \pm 0.3^{\mathrm{b}}$ & $1.3 \pm 0.2^{\mathrm{b}}$ & $2.1 \pm 0.3^{\mathrm{c}}$ & $1.0 \pm 0.1^{\mathrm{c}}$ \\
\hline & $\mathrm{F}$ & $0.9 \pm 0.2^{\mathrm{a}}$ & $1.5 \pm 0.4^{\mathrm{a}}$ & $1.3 \pm 0.3^{\mathrm{b}}$ & $1.3 \pm 0.3^{\mathrm{b}}$ & $1.7 \pm 0.4^{\mathrm{c}}$ & $1.1 \pm 0.3^{\mathrm{c}}$ \\
\hline \multirow{2}{*}{$\mathrm{DB}(\mathrm{mg} / \mathrm{dL})$} & M & $0.9 \pm 0.1^{\mathrm{a}}$ & $0.8 \pm 0.1^{\mathrm{a}}$ & $1.2 \pm 0.3^{\mathrm{b}}$ & $0.7 \pm 0.1^{\mathrm{a}}$ & $0.9 \pm 0.2^{\mathrm{a}}$ & $0.5 \pm 0.1^{\mathrm{b}}$ \\
\hline & $\mathrm{F}$ & $0.3 \pm 0.1^{\mathrm{a}}$ & $0.7 \pm 0.3^{\mathrm{a}}$ & $0.7 \pm 0.3^{\mathrm{b}}$ & $0.7 \pm 0.4^{\mathrm{a}}$ & $0.9 \pm 0.4^{\mathrm{c}}$ & $0.4 \pm 0.2^{\mathrm{b}}$ \\
\hline \multirow{2}{*}{$\begin{array}{l}\text { Prothrombin } \\
\text { concentration (\%) }\end{array}$} & M & $66.9 \pm 4.1^{\mathrm{a}}$ & $75.5 \pm 3.0^{\mathrm{a}}$ & $67.0 \pm 3.4^{\mathrm{a}}$ & $81.9 \pm 2.8^{\mathrm{a}}$ & $69.5 \pm 3.1^{\mathrm{a}}$ & $86.0 \pm 3.7^{\mathrm{b}}$ \\
\hline & $\mathrm{F}$ & $64.0 \pm 8.1^{\mathrm{a}}$ & $73.2 \pm 4.6^{\mathrm{a}}$ & $71.1 \pm 4.8^{\mathrm{b}}$ & $79.7 \pm 4.7^{\mathrm{a}}$ & $70.7 \pm 6.3^{\mathrm{b}}$ & $87.2 \pm 4.2^{\mathrm{b}}$ \\
\hline
\end{tabular}

Within each row, different superscript letters indicate a significant difference $(p \leq 0.05)$.

$\mathrm{KGE}$, Korean red ginseng extract; ALT, alanine transaminase; AST, aspartate transaminase; TP, total protein; TB, total bilirubin; DB, direct bilirubin. 
than in females. Albumin levels in control patients did not change significantly during the study period. However, it started a significant increase after 6 weeks of KGE administration.

The total bilirubin (TB) level was significantly higher in male than female patients in the two groups. The concentration of TB at the starting date was higher than the normal reference range $(0.2-1.0 \mathrm{mg} / \mathrm{dL})$. The TB concentration was higher in males than in females in the control group, while it was higher in females than in males in the group with KGE administration. Administration of KGE capsules at the two doses tested for 6 weeks resulted in a significant decrease in TB in both male and female patients. More improvement was also achieved when the treatment period was prolonged to 11 weeks, and the benefits were more pronounced in males than in females at week 11.

Results indicated that direct bilirubin (DB) concentration was also affected in a similar manner to the TB concentration in all patients at the start of the study. The data related to DB revealed that $\mathrm{DB}$ concentration was significantly higher than the normal reference range (up to $0.3 \mathrm{mg} / \mathrm{dL}$ ) in both groups of patients at the beginning of the study. The same data showed that DB was higher in males than females. Administration of KGE capsules at a dose of $900 \mathrm{mg} /$ day for the HCC patients and $600 \mathrm{mg} /$ day for the cirrhotics for 6 weeks was associated with a significant improvement in DB concentration, although it was still higher than normal. Moreover, the administration of KGE at the same dose for 11 weeks resulted in a more significant decrease in DB, although it did not normalize. Furthermore, the results also indicated that the effects of KGE were more pronounced in female patients than in males. The concentration of DB in the control patients group continued to increase from time zero until the 6th week, and then it started to decrease, presumably due to the medication they received. However, the concentration of DB in the KGE-treated group decreased during the first 6 weeks and continued to decrease through the 11 week, although the treatment with KGE for this period did not normalize DB.

The prothrombin concentration (PC) for males and females in the control patients who received their prescribed treatments only was also lower in males than in females. Administration of KGE plus the medication resulted in a significant increase in PC by week 6 , and this improvement was more pronounced in males than females. In a similar manner, the combined treatment with KGE capsules and the medication for 11 weeks resulted in a significant improvement in PC back towards the normal reference range. Moreover, there was no significant difference between male and female patients at the end of week 11. No significant improvement was found in the control patients subjected to medical treatment only during the study period. PC increased gradually from the starting date until week 6 , but did not change significantly after that. The KGE-treated group of patients showed a gradual increase in PC, starting on the first day of KGE administration and continuing until the end of week 11.

At the end of the study period, patients with $\mathrm{HCV}$ and HCC (males and females) were separated, and the concentrations of HCV and alpha-fetoprotein (AFP) were evaluated. The results presented in Fig. 1 indicate that administration of KGE capsules at a dose of 600 $\mathrm{mg}$ /day for both male and female patients with $\mathrm{HCV}$ resulted in a significant decrease in the viral concentration compared with the control patients with HCV. Moreover, the reduction in viral concentration was more pronounced in males than females.

The results presented in Fig. 2 also indicated that AFP was significantly higher in the control patients. Moreover, the level of AFP was higher in males than females. Administration of KGE at a dose of $900 \mathrm{mg} /$ day for 11 weeks resulted

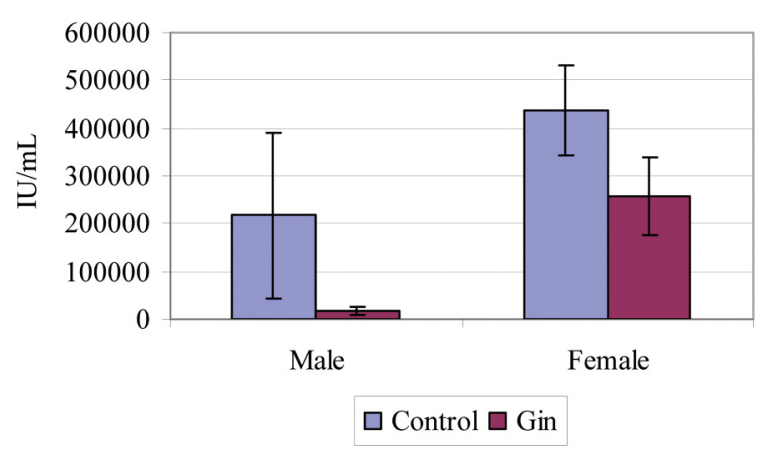

Fig. 1. Effects of ginseng administration on viral concentration in male and female patients with cirrhosis who were treated with ginseng capsules (600 mg/day) for 11 weeks.

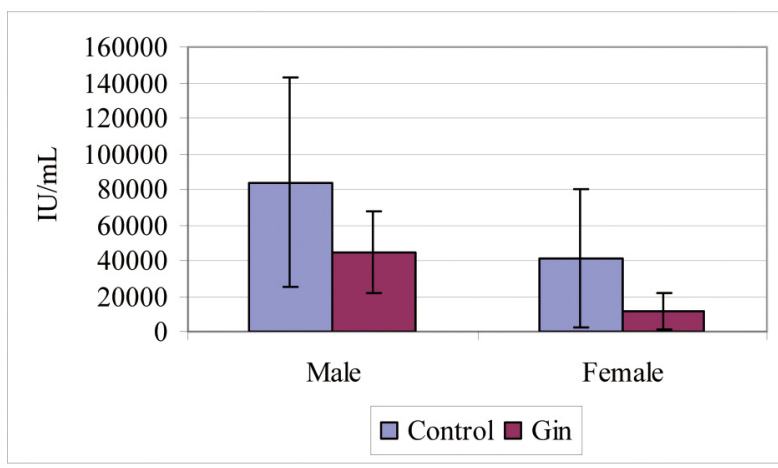

Fig. 2. Effects of ginseng administration on alpha-fetoprotein in male and female patients with hepatocellular carcinoma and treated with ginseng capsules ( $900 \mathrm{mg} /$ day) for 11 weeks. 
in a significant decrease in AFP, and this decrease was more pronounced in females than in males.

\section{DISCUSSION}

HCV infection is a major cause of chronic hepatitis affecting approximately 175 million people worldwide [13]. The prevalence of cirrhosis from chronic HCV infection and the incidence of its complications are expected to increase all around the world over the next 10-20 years $[13,14]$. Currently, intravenous drug use, unprotected sex with multiple partners, and viral exposure during medical procedures, such as surgery, dialysis, and dental treatment, are factors associated with the highest degree of risk for HCV infection [15,16]. Healthcare employees are at risk for acute hepatitis $\mathrm{C}$ through accidental exposure, such as needle stick injury; however, recent reports indicate that the risk for HCV transmission after needle stick injury is lower than previously believed (mean value $0.75 \%$; in Europe 0.42\%; in Eastern Asia 1.5\%) [17]. Risk factor patterns apparently vary according to geography. For example, within many Western countries, intravenous drug use is the greatest risk factor, with sexual transmission and medical practices representing other less common risk factors [18]. Conversely, in Egypt, occupational exposure seems to be the greatest hazard, with intravenous drug use and sexual transmission being less important $[19,20]$. Although guidelines exist for the management of chronic hepatitis C [13], they do not specifically address acute hepatitis C. After exposure to $\mathrm{HCV}$, there is a window of 1-3 weeks before serum HCV RNA can be detected. In patients in whom symptoms are developing, the incubation period between exposure and appearance of symptoms can range from 2 to 12 weeks [21]. The most common symptoms are fatigue and jaundice, with dyspepsia and abdominal pain often being reported [22]. Given that most symptoms are non-specific, many patients do not consult a physician and do not receive a diagnosis during the acute phase [23] On the other hand, HCC is the fifth most common cancer in the world. Approximately 315,000 cases of HCC are diagnosed each year, accounting for $4.1 \%$ of all new human cancer cases [24]. The highest incidence rates of HCC are in Asia and sub-Saharan Africa, where there is a marked increase in incidence in younger age groups [25]. Nevertheless, both incidence and mortality rates are also increasing in some countries in North America and Europe [26,27]. Although various nonsurgical treatment modalities have been developed and surgical techniques are much improved, none of these therapies has significantly improved the extremely poor prognosis of patients with HCC. Thus, searching for new compounds for the treatment of HCC is the aim of numerous studies, and many works have focused on plant-derived compounds that are known to have curative potential from traditional medicines.

In the current study, we evaluated the anticancer and protective effect of KGE in Egyptian patients with liver cirrhosis and/or liver cancer. Male and female patients were administered medical treatments supplemented with $900 \mathrm{mg}$ /day KGE for liver cancer patients and $600 \mathrm{mg} /$ day KGE for patients with liver cirrhosis for 11 weeks. The doses of KGE used in the current study were based on our previous work in experimental animals [28] and others. The results revealed that both types of patients (HCC and cirrhotics) showed a significant increase in all biochemical parameters tested. In males and females with cirrhosis of the liver, liver enzymes showed a significant increase, beginning on the starting day and did not normalize or even decrease significantly, although they received medical therapy alone. The first indication of hepatic injury is an elevated ALT level, which can occur 4-12 weeks after viral exposure [29]. Other criteria that can aid in diagnosing HCV infection include significantly elevated ALT levels $(>10 \times$ upper limit of normal [ULN] or $>20 \times$ ULN), known or suspected exposure to $\mathrm{HCV}$, and increasing numbers of reactive proteins in a recombinant immunoblot assay confirmation test [30,31]. Male and female patients in both groups showed an increase in ALT, AST, and urea, accompanied by significant decreases in total protein and albumin. The increases in transaminases in HCC and HVC patients are indicative of changes in the hepatic tissues and biliary system [28,32], whereas increased levels of urea with the decreased levels of total protein and albumin may indicate protein catabolism as a result of liver damage and/or renal dysfunction [33,34]. Moreover, HCV infection causes a liver disease that becomes chronic in $70 \%$ to $80 \%$ of patients and leads to severe complications, such as cirrhosis and liver cancer after many years [35]. The current results also indicate that the viral concentration was very high in male and female patients with an $\mathrm{HCV}$ infection. Moreover, female patients had higher viral concentrations than males. AFP was found to be very high in male and female patients with HCC. Generally, the current results indicate that medical therapy alone was not fully effective in either male or female patients with $\mathrm{HCC}$ or $\mathrm{HCV}$.

Both male and female patients who received their medical therapy supplemented with KGE showed a 
significant improvement in all the parameters tested. Liver enzymes showed a significant decrease in both groups of patients. Moreover, the viral concentration decreased significantly in HCV patients. The response to this protocol was higher in males than in females. A $91.8 \%$ decrease in viral concentration was found in males who received the antiviral therapy plus two KGE capsules per day for 11 weeks, whereas a $41.6 \%$ decrease was found in female patients who received the same dose for the same period. On the other hand, AFP decreased significantly in males and females who took their medical therapy along with three KGE capsules per day for 11 weeks. Furthermore, the improvement in AFP was more pronounced in females than males; the reduction ratio reached $71 \%$ in females and $47 \%$ in males.

According to Attele et al. [36], the major components of Panax ginseng cultivated in Korea are ginsenosides. Numerous researchers have contributed to the accumulation of evidence that ginsenosides are responsible for many biological activities including anti-inflammatory, antiallergic, and anti-tumour activities seen in cell culture or in vivo studies following intraperitoneal or intravenous injection of experimental animals [37,38]. However, others have proposed the concept that these plant glycosides act as prodrugs that are metabolized to active form by deglycosylation by intestinal bacterial [39,40]. Many studies have revealed that the anticancer activities of ginsenosides after oral administration are probably attributable to metabolites formed by intestinal bacteria $[41,42]$ and fatty acid esterification [43]. The components of red ginseng are known as 20(S)-ginsenoside $\mathrm{Rg} 3$, ginsenosides $\mathrm{Rh} 2$, Rs1, or Rs2, Rs3, Rs4 and Rg5, plus notoginsenoside-R4 in the protopanaxadiol group, and 20(R)-ginsenoside $\mathrm{Rg} 2,20(R)$-ginsenoside- $\mathrm{Rh} 1$, ginsenosides $\mathrm{Rh} 4$ and $\mathrm{F} 4$ in the protopanaxatriol group. Malonyl-ginsenoside$\mathrm{Rb} 1, \mathrm{Rb} 2, \mathrm{Rc}$, and $\mathrm{Rd}$ are found only in white ginseng [44]. However, Bae et al. [45,46] isolated and identified a novel ginseng saponin metabolite, formed from ginsenosides $\mathrm{Rb} 1, \mathrm{Rb} 2$, and $\mathrm{Rc}$ by the human intestinal bacteria deglycosylation, after giving ginseng extract to humans and rats. This novel ginseng saponin was 20-O-( $\beta$-D-glucopyranosyl)-20(S)-protopanaxadiol (IH901, compound K, or M1). Because IH-901 was detected as one of the major metabolites in urine and blood after the oral administration, IH-901 is likely a major form of protopanaxadiol saponin absorbed from the intestine $[47,48]$. IH-901 inhibits glucose uptake by tumour cells [49], and exhibits an anti-metastatic effect in vivo [50]. Moreover, IH-901 possesses chemopreventive and chemotherapeutic potential, because it shows antigenotoxic and anticlastogenic activity induced by benzo[a]pyrene [10], anti-tumour activity in cisplatin-resistant pulmonary adenocarcinoma cells [9], and reversal of multidrug resistance in tumor cells [8]. However, the anti-proliferation and apoptotic actions of IH-901 in human hepatocellular carcinoma cells are not clearly understood.

Present cancer chemotherapeutics exert part of their pharmacological effects by triggering apoptotic cell death, and the induction of apoptosis in tumor cells has become a strategy in cancer treatment [51]. Apoptosis can be initiated by extracellular and intracellular signals that trigger a complex machinery of pro-apoptotic proteases and mitochondrial changes. It is the integration of multiple survival and death signals that determine whether a cell survives or undergoes apoptosis. Moreover, IH-901 was shown to induce apoptosis in several different cancer cell lines [12,52], and several apoptosis-related molecules play important regulatory roles in $\mathrm{IH}-901$-induced tumor cell death [53,54]. Along the same lines, Ming et al. [55] suggested that IH-901 induced apoptotic cell death concurrently with cell cycle arrest in SMMC7721 cells. Similar effects of IH-901 in inhibiting the cell growth have been reported previously in other cancer cell lines [54].

Cytochrome $c$ normally resides in the mitochondrial intermembrane space, where it serves as a transducer of electrons in the respiratory chain. However, in chemicalinduced apoptosis, mitochondria also play a central role in the commitment of cells to apoptosis [56]. It has been demonstrated that several anti-tumor drugs with diverse intracellular targets can cause mitochondrial release and cytosolic accumulation of cytochrome $c$ [57]. After release from mitochondria, cytochrome $c$ binds with Apaf- 1 and participates in the activation of caspase-9 (an initiator). Activated caspase-9 then activates caspase-3 (an effector). Initiator caspases and effector caspases act together to augment the death signal and finally lead to a unilateral process of apoptosis [58,59]. Previous studies have established that IH-901 plays an important role in triggering the mitochondria-mediated apoptosis pathway in different cancer cell lines, in which caspases are the central components [11,60]. Ming et al. [55] showed that cytochrome $c$ was upregulated, and procaspase-3 and procaspase- 9 were downregulated in a concentrationdependent manner by IH-901 treatment and thus activated the proteolysis. Moreover, cytochrome $c$ can initiate a complex series of caspase activation events, ultimately resulting in apoptosis. The interaction between the antiapoptotic and pro-apoptotic Bcl-2 family members has been shown to regulate this event [61]. It is commonly believed that Bcl-2 and its homolog Bcl-XL have a role 
in preventing mitochondrial membrane disruption and the release of cytochrome $c$ and other pro-apoptotic factors, while Bax/Bak-like proteins promote these events $[62,63]$. The total expression rate of these two contrary proteins might partly indicate the fate of cells.

On the other hand, IH-901-induced apoptosis in SMMC7721 cell lines might act through increased expression of $\mathrm{p} 53$, a tumor suppressor gene [55]. Activation of $\mathrm{p} 53$ changes the ratio of $\mathrm{Bcl}-2 / \mathrm{Bax}$ and $\mathrm{Bcl}-\mathrm{XL} / \mathrm{Bax}$, leading to the release of cytochrome $c$ from mitochondria. Thus, proteins from the Bcl-2 family might act as downstream signal carriers in the process of IH-901-induced apoptosis in the human hepatocellular carcinoma cell line SMMC7721.

Sterols, other components of Panax ginseng, also have antineoplastic activity. Studies have shown that sterolenriched (such stigmasterol and sitosterol) diets reduce the plasma cholesterol concentrations [64,65], have antiinflammatory actions [66,67], and display analgesic and anti-mutagenic effects [67,68]. Moreover, Yun et al. [69] used a mixture of Rg3 and Rg5, present in large amounts in red ginseng, and showed that they reduced the incidence of lung adenoma induced by benzo(a) pyrene in mice to $45.0 \%$ (inhibition rate, $25.0 \%$ ). They concluded that $\mathrm{Rg} 3+\mathrm{Rg} 5$ had anticarcinogenic effects. Similar to the current observations, Nishino et al. [70] reported that oral administration of red ginseng extracts significantly suppressed spontaneous liver tumour formation in $\mathrm{C} 3 \mathrm{H} / \mathrm{He}$ male mice.

According to Antonelli et al. [71], HCV is able to affect B-lymphocytes through the $\mathrm{CD}$ receptor, inducing a polyclonal B-cell activation that leads to the production of cryoglobulins, rheumatoid factor, and several autoantibodies. On the other hand, epidemiological evidence clearly indicates that among the mechanisms that have been implicated in the pro-carcinogenic effect of $\mathrm{HCV}$ infections, increased production of reactive oxygen species in the liver seems to have a major pathogenic role in the progression from chronic inflammation to cancer [72].

Recent data have also demonstrated that HCV is capable of inducing the active production of free radicals per se, not just through inflammation, a feature peculiar to this virus and the specific activity of its core protein [73]. Moreover, our results in rats indicated that one of the manifestations of the incidence of cancer is the formation of free radicals, which plays an important role in lipid peroxidation, liver damage, and carcinogenicity [28].

It is well-documented that Panax ginseng C.A. Meyer attenuates lipid peroxidation and is also capable of scavenging reactive oxygen species $[28,74]$. These results support the hypothesis that ginseng has cancer preventive and antiviral effects, as suggested by the earlier animal experiments that suggested that Korean Panax ginseng had non-organ specific preventative effects against cancer [75].

In conclusion, the results of the current study indicate that $\mathrm{KGE}$ acts as liver cancer preventative as well as an antiviral agent against HCV. In HCV patients, the mechanism of KGE as an antiviral may be due to 1) its ability to increase cellular immunity, 2) its role in the scavenging free radicals generated by the virus, and 3) the increase in antioxidant enzymes in the cell. The mechanisms by which ginseng induces its anticancer effects include 1) its antioxidants properties, 2) an increase in antioxidant enzymes in the cell, 3) its free radicals scavenger properties, 4) an increase in the regeneration of liver cells, 5) a decrease in lipid peroxidation, and 6) inhibition of cytochrome P450 and/or activation of cytochrome P53.

\section{ACKNOWLEDGMENTS}

This work was fully supported by the grant (2007) from the Korean Society of Ginseng funded by Korea Ginseng Corporation (KGC). The capsule of KRG used in this study was supplied by KGC.

\section{REFERENCES}

1. El-Serag HB, Rudolph KL. Hepatocellular carcinoma: epidemiology and molecular carcinogenesis. Gastroenterology 2007;132:2557-2576.

2. Velazquez RF, Rodriguez M, Navascues CA, Linares A, Perez R, Sotorrios NG, Martinez I, Rodrigo L. Prospective analysis of risk factors for hepatocellular carcinoma in patients with liver cirrhosis. Hepatology 2003;37:520-527.

3. Rahman El-Zayadi A, Abaza H, Shawky S, Mohamed MK, Selim OE, Badran HM. Prevalence and epidemiological features of hepatocellular carcinoma in Egypt: a single center experience. Hepatol Res 2001;19:170-179.

4. Farazi PA, DePinho RA. Hepatocellular carcinoma pathogenesis: from genes to environment. Nat Rev Cancer 2006;6:674-687.

5. Soldati F. Panax ginseng: standardization and biological activity. In: Cutler SJ, Cutler HG eds. Biologically active natural products: pharmaceuticals. Boca Raton (FL): CRC Press, 2000. p. 209-232.

6. Barnes P, Powell-Griner E, McFann K, Nahin R. Complementary and alternative medicine use among adults: United States, 2002. Bethesda (MD): National Center for Complementary and Alternative Medicine, 2004. 
7. Hasegawa H, Sung JH, Matsumiya S, Uchiyama M. Main ginseng saponin metabolites formed by intestinal bacteria. Planta Med 1996;62:453-457.

8. Hasegawa H, Sung JH, Matsumiya S, Uchiyama M, Inouye Y, Kasai R, Yamasaki K. Reversal of daunomycin and vinblastine resistance in multidrug-resistant $\mathrm{P} 388$ leukemia in vitro through enhanced cytotoxicity by triterpenoids. Planta Med 1995;61:409-413.

9. Lee SJ, Sung JH, Lee SJ, Moon CK, Lee BH. Antitumor activity of a novel ginseng saponin metabolite in human pulmonary adenocarcinoma cells resistant to cisplatin. Cancer Lett 1999;144:39-43.

10. Lee BM, Lee SK, Kim HS. Inhibition of oxidative DNA damage, 8-OHdG, and carbonyl contents in smokers treated with antioxidants (vitamin $\mathrm{E}$, vitamin $\mathrm{C}$, beta-carotene and red ginseng). Cancer Lett 1998;132:219-227.

11. Lee SJ, Ko WG, Kim JH, Sung JH, Moon CK, Lee BH. Induction of apoptosis by a novel intestinal metabolite of ginseng saponin via cytochrome c-mediated activation of caspase-3 protease. Biochem Pharmacol 2000;60:677-685.

12. Choi HH, Jong HS, Park JH, Choi S, Lee JW, Kim TY, Otsuki T, Namba M, Bang YJ. A novel ginseng saponin metabolite induces apoptosis and down-regulates fibroblast growth factor receptor 3 in myeloma cells. Int J Oncol 2003;23:1087-1093.

13. Dienstag JL, McHutchison JG. American Gastroenterological Association technical review on the management of hepatitis C. Gastroenterology 2006;130:231-264.

14. Davis GL, Albright JE, Cook SF, Rosenberg DM. Projecting future complications of chronic hepatitis $\mathrm{C}$ in the United States. Liver Transpl 2003;9:331-338.

15. Esteban JI, Sauleda S, Quer J. The changing epidemiology of hepatitis C virus infection in Europe. J Hepatol 2008; 48:148-162.

16. Martinez-Bauer E, Forns X, Armelles M, Planas R, Sola R, Vergara M, Fabregas S, Vega R, Salmeron J, Diago M, et al. Hospital admission is a relevant source of hepatitis $\mathrm{C}$ virus acquisition in Spain. J Hepatol 2008;48:20-27.

17. Kubitschke A, Bader C, Tillmann HL, Manns MP, Kuhn S, Wedemeyer $\mathrm{H}$. Injuries from needles contaminated with hepatitis $\mathrm{C}$ virus: how high is the risk of seroconversion for medical personnel really? Internist (Berl) 2007;48: 1165-1172.

18. Wiegand J, Buggisch P, Boecher W, Zeuzem S, Gelbmann CM, Berg T, Kauffmann W, Kallinowski B, Cornberg M, Jaeckel E, et al. Early monotherapy with pegylated interferon alpha-2b for acute hepatitis $\mathrm{C}$ infection: the HEP-NET acuteHCV-II study. Hepatology 2006;43:250-256.

19. Kamal SM, Fouly AE, Kamel RR, Hockenjos B, Al Tawil A, Khalifa KE, He Q, Koziel MJ, El Naggar KM, Rasenack
$\mathrm{J}$, et al. Peginterferon alfa- $2 \mathrm{~b}$ therapy in acute hepatitis $\mathrm{C}$ : impact of onset of therapy on sustained virologic response. Gastroenterology 2006;130:632-638.

20. Kamal SM, Moustafa KN, Chen J, Fehr J, Abdel Moneim A, Khalifa KE, El Gohary LA, Ramy AH, Madwar MA, Rasenack J, et al. Duration of peginterferon therapy in acute hepatitis C: a randomized trial. Hepatology 2006; 43:923-931.

21. Orland JR, Wright TL, Cooper S. Acute hepatitis C. Hepatology 2001;33:321-327.

22. World Health Organization. Hepatitis C. Geneva: World Health Organization, 2000.

23. Santantonio T, Wiegand J, Gerlach JT. Acute hepatitis C: current status and remaining challenges. J Hepatol 2008; 49:625-633.

24. Howe HL, Wingo PA, Thun MJ, Ries LA, Rosenberg HM, Feigal EG, Edwards BK. Annual report to the nation on the status of cancer (1973 through 1998), featuring cancers with recent increasing trends. J Natl Cancer Inst 2001;93:824842.

25. Ogunbiyi JO. Hepatocellular carcinoma in the developing world. Semin Oncol 2001;28:179-187.

26. Taylor-Robinson SD, Foster GR, Arora S, Hargreaves S, Thomas HC. Increase in primary liver cancer in the UK, 1979-94. Lancet 1997;350:1142-1143.

27. El-Serag HB, Mason AC. Rising incidence of hepatocellular carcinoma in the United States. N Engl J Med 1999;340: 745-750.

28. Abdel-Wahhab MA, Hassan NS, El-Kady AA, Khadrawy YA, El-Nekeety AA, Mohamed SR, Sharaf HA, Mannaa FA. Red ginseng extract protects against aflatoxin $\mathrm{B} 1$ and fumonisins-induced hepatic pre-cancerous lesions in rats. Food Chem Toxicol 2010;48:733-742.

29. World Gastroenterology Organisation practice guideline: management of acute viral hepatitis. Available from: http:// www.worldgastroenterology.org/assets/downloads/en/pdf/ guidelines/02_acute hepatitis.pdf.

30. Mondelli MU, Cerino A, Cividini A. Acute hepatitis C: diagnosis and management. J Hepatol 2005;42 Suppl(1):S108S114.

31. Heller T, Rehermann B. Acute hepatitis C: a multifaceted disease. Semin Liver Dis 2005;25:7-17.

32. Abdel-Wahhab MA, Amer HA, Hassan NS, Hassan AM, Naguib K. Effects of garlic and cabbage extracts on fumonisin-induced toxicity in rats. J Egypt Soc Toxicol 2002;26:112.

33. Abdel-Wahhab MA, Aly SE. Antioxidants and radical scavenging properties of vegetable extracts in rats fed aflatoxincontaminated diet. J Agric Food Chem 2003;51:2409-2414.

34. Abdel-Wahhab MA, Aly SE. Antioxidant property of Nigella 
sativa (black cumin) and Syzygium aromaticum (clove) in rats during aflatoxicosis. J Appl Toxicol 2005;25:218-223.

35. Palazzi C, D'Angelo S, Olivieri I. Hepatitis C virus-related arthritis. Autoimmun Rev 2008;8:48-51.

36. Attele AS, Wu JA, Yuan CS. Ginseng pharmacology: multiple constituents and multiple actions. Biochem Pharmacol 1999; 58:1685-1693.

37. Shin HR, Kim JY, Yun TK, Morgan G, Vainio H. The cancerpreventive potential of Panax ginseng: a review of human and experimental evidence. Cancer Causes Control 2000;11:565576.

38. Park EK, Choo MK, Han MJ, Kim DH. Ginsenoside Rh1 possesses antiallergic and anti-inflammatory activities. Int Arch Allergy Immunol 2004;133:113-120.

39. Kobashi K, Akao T, Hattori M, Namba T. Metabolism of drugs by intestinal bacteria. Bifidobact Microflora 1992; 11:9-23.

40. Kobashi K, Akao T. Relation of intestinal bacteria to pharmacological effects of glycosides. Biosci Microflora 1997; 16:1-7.

41. Wakabayashi C, Hasegawa H, Murata J, Saiki I. In vivo antimetastatic action of ginseng protopanaxadiol saponins is based on their intestinal bacterial metabolites after oral administration. Oncol Res 1997;9:411-417.

42. Wakabayashi C, Hasegawa H, Murata J, Saiki I. The expression of in vivo antimetastatic effect of ginseng protopanaxatriol saponins is mediated by their intestinal bacterial metabolites after oral administration. J Tradit Med 1997;14:180-185.

43. Hasegawa H, Suzuki R, Nagaoka T, Tezuka Y, Kadota S, Saiki I. Prevention of growth and metastasis of murine melanoma through enhanced natural-killer cytotoxicity by fatty acid-conjugate of protopanaxatriol. Biol Pharm Bull 2002;25:861-866.

44. Yun TK. Panax ginseng: a non-organ-specific cancer preventive? Lancet Oncol 2001;2:49-55.

45. Bae EA, Park SY, Kim DH. Constitutive beta-glucosidases hydrolyzing ginsenoside $\mathrm{Rb} 1$ and $\mathrm{Rb} 2$ from human intestinal bacteria. Biol Pharm Bull 2000;23:1481-1485.

46. Bae EA, Choo MK, Park EK, Park SY, Shin HY, Kim $\mathrm{DH}$. Metabolism of ginsenoside $\mathrm{R}(\mathrm{c})$ by human intestinal bacteria and its related antiallergic activity. Biol Pharm Bull 2002;25:743-747.

47. Akao T, Kanaoka M, Kobashi K. Appearance of compound $\mathrm{K}$, a major metabolite of ginsenoside $\mathrm{Rb} 1$ by intestinal bacteria, in rat plasma after oral administration: measurement of compound $\mathrm{K}$ by enzyme immunoassay. Biol Pharm Bull 1998;21:245-249.

48. Akao T, Kida H, Kanaoka M, Hattori M, Kobashi K. Intestinal bacterial hydrolysis is required for the appearance of compound $\mathrm{K}$ in rat plasma after oral administration of ginsenoside Rb1 from Panax ginseng. J Pharm Pharmacol 1998;50:1155-1160.

49. Hasegawa H, Matsumiya S, Uchiyama M, Kurokawa T, Inouye Y, Kasai R, Ishibashi S, Yamasaki K. Inhibitory effect of some triterpenoid saponins on glucose transport in tumor cells and its application to in vitro cytotoxic and antiviral activities. Planta Med 1994;60:240-243.

50. Hasegawa H, Sung JH, Huh JH. Ginseng intestinal bacterial metabolite IH901 as a new anti-metastatic agent. Arch Pharm Res 1997;20:539-544.

51. Kim SE, Lee YH, Park JH, Lee SK. Ginsenoside-Rs4, a new type of ginseng saponin concurrently induces apoptosis and selectively elevates protein levels of p53 and p21WAF1 in human hepatoma SK-HEP-1 cells. Eur J Cancer 1999; 35:507-511.

52. Wakabayashi C, Murakami K, Hasegawa H, Murata J, Saiki I. An intestinal bacterial metabolite of ginseng protopanaxadiol saponins has the ability to induce apoptosis in tumor cells. Biochem Biophys Res Commun 1998;246:725-730.

53. Oh SH, Yin HQ, Lee BH. Role of the Fas/Fas ligand death receptor pathway in ginseng saponin metabolite-induced apoptosis in HepG2 cells. Arch Pharm Res 2004;27:402406.

54. Yim HW, Jong HS, Kim TY, Choi HH, Kim SG, Song SH, Kim J, Ko SG, Lee JW, Kim TY, et al. Cyclooxygenase-2 inhibits novel ginseng metabolite-mediated apoptosis. Cancer Res 2005;65:1952-1960.

55. Ming YL, Song G, Chen LH, Zheng ZZ, Chen ZY, Ouyang GL, Tong QX. Anti-proliferation and apoptosis induced by a novel intestinal metabolite of ginseng saponin in human hepatocellular carcinoma cells. Cell Biol Int 2007;31:12651273.

56. Herr I, Debatin KM. Cellular stress response and apoptosis in cancer therapy. Blood 2001;98:2603-2614.

57. Liu X, Kim CN, Yang J, Jemmerson R, Wang X. Induction of apoptotic program in cell-free extracts: requirement for dATP and cytochrome c. Cell 1996;86:147-157.

58. Srinivasula SM, Ahmad M, Fernandes-Alnemri T, Alnemri ES. Autoactivation of procaspase-9 by Apaf-1-mediated oligomerization. Mol Cell 1998;1:949-957.

59. Slee EA, Harte MT, Kluck RM, Wolf BB, Casiano CA, Newmeyer DD, Wang HG, Reed JC, Nicholson DW, Alnemri ES, et al. Ordering the cytochrome c-initiated caspase cascade: hierarchical activation of caspases- $2,-3,-6,-7,-8$, and -10 in a caspase-9-dependent manner. J Cell Biol 1999;144: 281-292.

60. Oh SH, Lee BH. A ginseng saponin metabolite-induced apoptosis in HepG2 cells involves a mitochondria-mediated pathway and its downstream caspase- 8 activation and Bid cleavage. Toxicol Appl Pharmacol 2004;194:221- 
229.

61. Adams JM, Cory S. The Bcl-2 protein family: arbiters of cell survival. Science 1998;281:1322-1326.

62. Gross A, McDonnell JM, Korsmeyer SJ. BCL-2 family members and the mitochondria in apoptosis. Genes Dev 1999;13:1899-1911.

63. Korsmeyer SJ, Wei MC, Saito M, Weiler S, Oh KJ, Schlesinger PH. Pro-apoptotic cascade activates BID, which oligomerizes BAK or BAX into pores that result in the release of cytochrome c. Cell Death Differ 2000;7:1166-1173.

64. Jones PJ, Ntanios FY, Raeini-Sarjaz M, Vanstone CA. Cholesterol-lowering efficacy of a sitostanol-containing phytosterol mixture with a prudent diet in hyperlipidemic men. Am J Clin Nutr 1999;69:1144-1150.

65. Cleghorn CL, Skeaff CM, Mann J, Chisholm A. Plant sterol-enriched spread enhances the cholesterol-lowering potential of a fat-reduced diet. Eur J Clin Nutr 2003;57: 170-176.

66. Navarro A, De las Heras B, Villar A. Anti-inflammatory and immunomodulating properties of a sterol fraction from Sideritis foetens Clem. Biol Pharm Bull 2001;24: 470-473.

67. Aboutabl EA, Nassar MI, Elsakhawy FM, Maklad YA, Osman AF, El-Khrisy EA. Phytochemical and pharmacological studies on Sideritis taurica Stephan ex Wild. J Ethnopharmacol 2002;82:177-184.

68. Villasenor IM, Angelada J, Canlas AP, Echegoyen D. Bio- activity studies on beta-sitosterol and its glucoside. Phytother Res 2002;16:417-421.

69. Yun TK, Lee YS, Choi KJ, Lee YH, Yun HY. Anticarcinogenicity of various ginseng fractions and components in red ginseng using Yun's anticarcinogenicity test model. J Korean Assoc Cancer Prev 2000;5:186-192.

70. Nishino H, Tokuda H, Ii T, Takemura M, Kuchide M, Kanazawa M, Mou XY, Bu P, Takayasu J, Onozuka M, et al. Cancer chemoprevention by ginseng in mouse liver and other organs. J Korean Med Sci 2001;16 Suppl:S66-S69.

71. Antonelli A, Ferri C, Galeazzi M, Giannitti C, Manno D, MieliVergani G, Menegatti E, Olivieri I, Puoti M, Palazzi C, et al. HCV infection: pathogenesis, clinical manifestations and therapy. Clin Exp Rheumatol 2008;26(1 Suppl 48):S39-S47.

72. Farinati F, Cardin R, Bortolami M, Burra P, Russo FP, Rugge M, Guido M, Sergio A, Naccarato R. Hepatitis C virus: from oxygen free radicals to hepatocellular carcinoma. J Viral Hepat 2007; 14:821-829.

73. Osman HG, Gabr OM, Lotfy S, Gabr S. Serum levels of bcl2 and cellular oxidative stress in patients with viral hepatitis. Indian J Med Microbiol 2007;25:323-329.

74. Abdel-Wahhab MA, Ahmed HH. Protective effect of Korean Panax ginseng against chromium VI toxicity and free radicals generation in rats. J Ginseng Res 2004;28:11-17.

75. Yun TK, Choi SY, Yun HY. Epidemiological study on cancer prevention by ginseng: are all kinds of cancers preventable by ginseng? J Korean Med Sci 2001;16 Suppl:S19-S27. 